\title{
E-learning Mobile Application Evaluation: Al- Zaytoonah University as a Case Study
}

\author{
Khalid Mohammad Jaber', Mohammad Abduljawad², Amal Ahmad ${ }^{3}$, \\ Mohammad Abdallah ${ }^{4}$, Mousa Salah ${ }^{5}$, and Nouh Alhindawi ${ }^{6}$ \\ ${ }^{1}$ Faculty of Science and Information Technology, Al-Zaytoonah University of \\ Jordan \\ e-mail: k.jaber@zuj.edu.jo \\ ${ }^{2}$ Faculty of Arts, Al-Zaytoonah University of Jordan \\ e-mail:m.abduljawad@zuj.edu.jo \\ ${ }^{3}$ Faculty of Engineering and Technology, Al-Zaytoonah University of Jordan \\ e-mail: amal.Q@zuj.edu.jo \\ ${ }^{4}$ Faculty of Science and Information Technology, Al-Zaytoonah University of \\ Jordan \\ e-mail: m.abdallah@zuj.edu.jo \\ ${ }^{5}$ Faculty of Architecture and Design, Al-Zaytoonah University of Jordan \\ e-mail: mosa.salah@zuj.edu.jo \\ ${ }^{6}$ Faculty of Science and Information Technology, Jadara University \\ e-mail: hindawi@jadara.edu.jo
}

\begin{abstract}
The E-learning standard is made up of several different quality elements and characteristics. Scholars examined the effectiveness of E-learning from a variety of perspectives. However, studies concerning the quality of E-learning mobile applications in particular are limited. Hence, the present study looks at the factors that influence the use of the E-learning mobile application by students and instructors of the Al-Zaytoonah University in Jordan throughout the academic year 2020-2021. The research instrument was initially validated. Subsequently, several quality factors were adopted to anticipate the factors affecting the adoption of the Elearning.ZUJ mobile application of nine hundred thirty-one students and one hundred nine instructors in this study. Regarding the actual usage of the E-learning mobile application for academic activities, in different proportions, the findings of this investigation were compatible with the adopted quality factors. Results revealed a significant positive relationship between the perceived reliability and demand for using E-learning applications. In addition to a significant positive relationship between the perceived benefit and behavioral intention to
\end{abstract}




\begin{abstract}
use E-learning mobile applications, the results show the following perceived quality factors: reliability, efficiency, integrity, usability, satisfaction, and supportability. The findings should be valuable to educational officials at the Al-Zaytoonah University of Jordan and elsewhere as existing technology could be improved or they could embrace new technology for academic purposes.
\end{abstract}

Keywords: E-learning mobile applications, E-learning quality, quality, quality factors.

\title{
1. Introduction
}

Mobile technologies have great potential for facilitating additional innovative educational methods. Simultaneously, these patterns in educational practices will likely help subject content learning and facilitate the development of communication, problem-solving, creativity, and other high-level skills among students [1]. However, despite the proposed advantages of using mobile computing devices for increasing computer accessibility, diverse teaching styles, and academic performance, currently, researchers found mixed results regarding the effects of mobile devices (e.g., [1] and [2]). Significantly few studies addressed how to best use mobile devices and the effectiveness of doing so. The present study aims to examine the elements that influence students' actual use of the E-learning mobile application for academic E-learning purposes. Many quality factors were investigated by several studies and were used to predict these characteristics as a commonly utilized model among theoretical models that explain consumers' acceptance and deployment of technology [3, 4]. Moreover, this concept has been widely adopted in industrialized countries as opposed to underdeveloped countries.

Several quality factors influence the consumers of new technology and how they use it. Research on university students and instructors' use of mobile applications for academic purposes in Jordan is limited. The current study focuses on the factors that influence the adoption of mobile applications in Al-Zaytoonah University of Jordan as one of the Jordanian universities. Knowing the elements that influence the use of E-learning mobile applications by students and instructors is crucial to increase future acceptance and usage. This study contributes by increasing research on the educational use of mobile applications in higher education institutions. Moreover, the study is theoretically significant [5] in a climate where research is scarce on this vital issue. A comprehensive analysis will be conducted to gain insight into the student, institutional, and academic variables in mobile application utilization. The review will also provide insight into techniques for encouraging students and instructors to download and use mobile applications for academic purposes. The findings of this study can be used by university administrators in charge of academic affairs to either boost student use of mobile applications or come up with practical approaches to persuade students to begin using them. 
Furthermore, the empirical data from this study will add to the body of knowledge in the disciplines of technology and academia by predicting adoption. Such data will also contribute to the domains of technology and academia by indicating Elearning mobile application acceptance and adoption.

The rest of this paper is organized as follows. Section 2 provides the literature review and shows how to create hypotheses. Section 3 explains the research strategy. Finally, Section 4 presents the study's empirical findings and comments, and Section 5 concludes the study and provides implications.

\section{Literature Review}

The usage of technology is currently affecting commercial operations and academic activities, which may be observed in how the arrival of the Internet has altered learning activities and knowledge dissemination. Higher education is experiencing extraordinary expansion because of the virtual delivery of academic programs made feasible by new and supporting technology [5, 6]. Many academics and scholars focus their arguments and discussions on the use of technology in education. The reason is that technology significantly affects education, with universities serving as the primary online education suppliers. Adopting technology in education appears to be critical in providing students with up-to-date information through more effective and creative techniques $[7,8]$.

The increased availability of mobile applications has brought change to the computing experience. Mobile application development entails the creation of computer programs for usage in mobile devices, such as smartphones, watches, and tablets. Mobile application development is done for a variety of operating systems, including Android, iOS, and Windows Mobile [9]. The most significant benefit of mobile phones is their portability. As mobile applications for smartphones are designed to execute a specific activity, they introduced a new approach to the service sector. In addition, the widespread adoption of these apps has significantly decreased time consumption because mobile devices provide easy access to a variety of goods and services [10].

As students use their phones for everything, the term "smartphone" was coined. Through smartphones, the globe became accessible, allowing students to obtain information from anywhere, decreasing the need for library visits and data searches, and making a mobile phone beneficial for such purposes. Mobile applications make information more accessible, and each has its own set of features for its own set of services. Traditional techniques do not let institutions provide equal attention to all 
pupils. However, technology makes this possible because institutional communication software may be used to communicate information to all students, such as new timetables, meetings and conferences, and other social events [11, 12]. Several well-known companies and developers have developed educational apps, and they have influenced individuals worldwide. Students and educators benefit from these apps because they enable easy and quick access to high-quality educational materials that were previously only available in libraries. These services are provided through apps in the form of e-Books, an e-Library, educational videos, and games [13].

Concerning the research on the use of mobile technology in education, Hwang et al. [14] provided a broad discussion of studies on mobile and ubiquitous learning published in six journals between 2001 and 2010. In their review of 154 articles, they discovered that the use of mobile and ubiquitous learning accelerated markedly in 2008. Researchers mainly studied students of higher education, and the fields most often researched were language arts, engineering, and computer technology. Frohberg et al. [15] categorized 102 mobilE-learning projects and found that most mobilE-learning activities occurred across different settings and within a physical context and an official environment, such as a classroom or workplace. Regarding the pedagogical roles that mobile devices play in education, most research used mobile devices primarily as a sort of reinforcement tool to stimulate motivation and strengthen engagement and secondarily as a content-delivery tool. Looi et al. [16] investigated the influence of mobile devices on seamless learning. Seamless learning refers to a learning model that students can learn whenever they want to learn in various scenarios. They can easily and quickly switch from one design or one context to another. Wong and Looi [17] selected and analyzed a sample of 54 articles on the use of mobile devices to facilitate seamless learning. They found that all 54 articles contained 10 features, including formal and informal education, personalized and social learning, and learning across multiple durations and locations.

Davis in [3] created and introduced the technology acceptance model as a theoretical extension of the theory of reasoned action. In comparison to other theoretical models that attempt to explain the relationship among user attitudes, contentment, and behavioral intention, this model is the most widely accepted one $[3,4]$. The theory of reasoned action $[18,19]$ predicts user acceptability based on perceived usability and perceived ease of use. The technology acceptance model expands on this concept and claims that perceived usability and perceived ease of use determine how users embrace technology. The technology acceptance model also claims that perceived ease of use directly affects perceived usability as a user will see technology as beneficial if it is simple to use. The model was then 
developed to anticipate the relationship between perceived usability and perceived ease of use $[4,5,20]$.

M. Abdul Jawad et al. [24] identified the strengths and weaknesses in the E-learning system after adding additional interactive content with students. Examples include voice and video chat, file and screen sharing, broadcasting lectures or classes, and interactive games. The authors measured student satisfaction and provided their experience to other educational institutions. They also found that the students are comfortable and interactive in using the Internet for different learning purposes.

The Al-Zaytoonah University of Jordan has developed a mobile application for Elearning compatible with Android, IOS, and Windows desktops. The app can be downloaded for free on Google Play Store for Android devices and Apple App Store for IOS devices. Students can use the ZUJ E-learning mobile application to access their academic services portal, email, E-learning portal, interactive lectures, examinations, homework, grades, and announcements. They can also contact their teachers, who are in charge of managing E-learning services and providing help.

\section{Research Strategy}

This study's experiment aims to identify the top quality elements that should be considered in any E-learning mobile app. Participants were given one week to review as many E-learning websites and applications as possible. Furthermore, they were given a list of quality characteristics and definitions to ensure that all participants had the same knowledge of the quality factors. Then, they were given two tasks. The first task is to choose the essential variables in their opinion and explain why they chose each one. The second one is to evaluate the Elearning.ZUJ mobile application according to each quality factor based on the availability of the quality factor in the mobile application from their point of view.

The following testable quality factors were developed based on the framework for examining the factors influencing the usage of the Elearning.ZUJ mobile application among students and instructors from various specializations in AlZaytoonah University of Jordan and existing research [20-25]:

Reliability, Efficiency, Integrity, Usability, Flexibility, Testability, Suitability, Performance, Evaluability, Manageability, Modifiability, Satisfaction and Supportability.

The quality factors have the same weight, and the participants can choose any one of them regardless of their reasons. 


\subsection{Participants}

The following are critical details about students and instructors who participated in the feedback process using the Elearning.ZUJ mobile application:

- The participants must fall into one of the following groups (students/instructors) from any specialization at the Al-Zaytoonah University of Jordan.

- Participants could include students in their third or fourth year of study and master's students. This prerequisite, along with the prior one, is to guarantee that students and instructors are aware of the quality assurance process, quality factors, and quality measurements.

- The student had to be registered in at least one E-learning course through the Elearning.ZUJ application; nevertheless, this does not exclude him from accessing the E-learning portal website. This requirement ensures that the participant has sufficient experience with the Elearning.ZUJ application. Instructors must also follow up on at least one course using the application.

- In this scenario, demographic parameters do not play a substantial role.

- The sample was taken exclusively at the Al-Zaytoonah University of Jordan. The researchers may expand the sample size in the future to include additional diverse participants.

\section{Results and Findings}

A total of 931 students and 109 instructors satisfied the selection criteria and responded to our queries. Notably, the COVID-19 pandemic has had a significant effect on the ongoing requirement for the Al-Zaytoonah University of Jordan to develop an E-learning application, considering the major quality factors as indicated in Figs. 1 and 2. Moreover, the research outcomes have helped, correspondingly, in the application's update to meet the highest quality standards. The majority of the explanations given by respondents were either directly or indirectly related to the COVID-19 pandemic. The epidemic has directly affected the university's teaching and learning, which has gone entirely online thanks to an E-learning portal and online lecture and meeting systems. Hence, the method in which professors and students interact has an influence on the decision.

The most critical quality factors that must be available in a mobile application that provides E-learning services from the respondents' point of view, which achieved rates higher than $95 \%$, are usability, flexibility, satisfaction and supportability. The most significant quality factor among them was usability, which is arguably a reasonable necessity for a mobile application because the most user-friendly applications assist users in saving time and effort. The suitability and manageability 
were the quality factors that received the lowest rates in terms of importance. The reason may be that users of mobile applications do not have the authority to manage, alter, or even evaluate them, and according to that, they do not care about such quality factors.

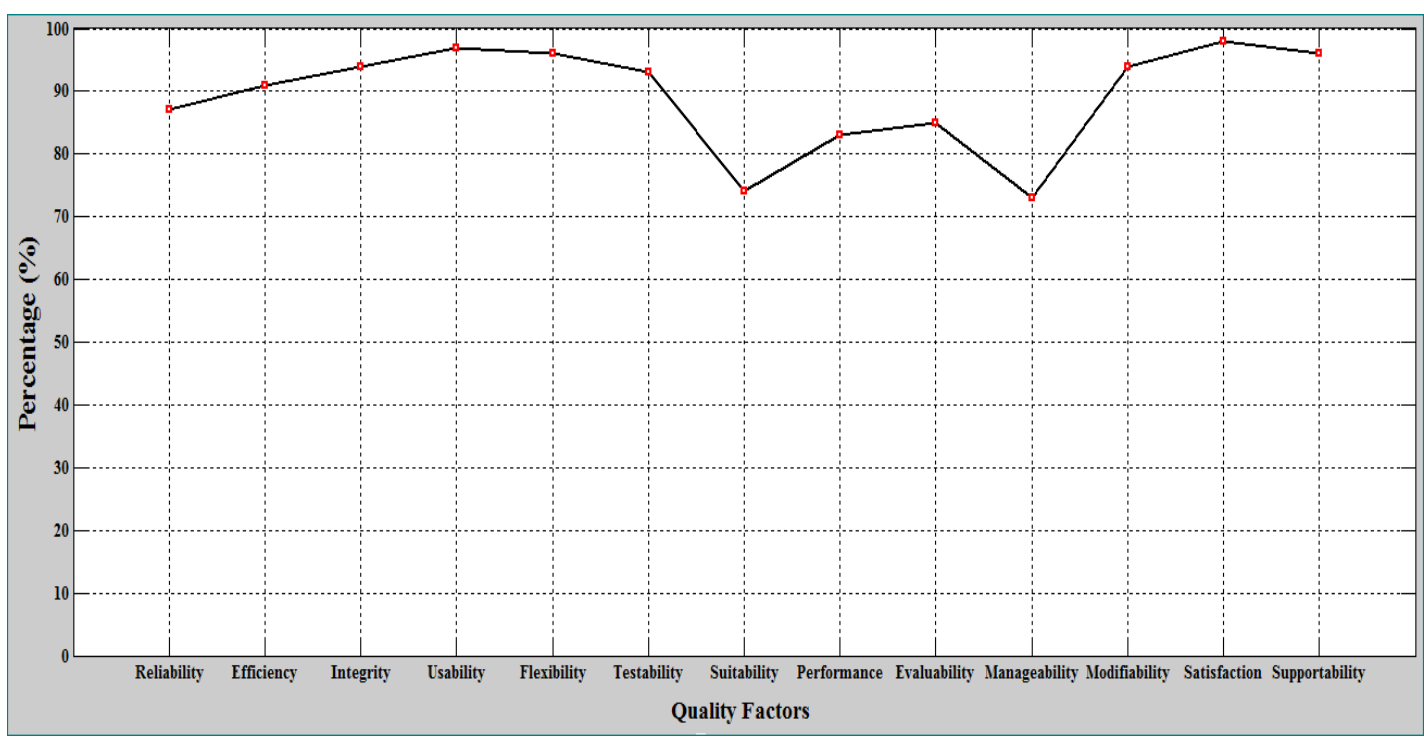

Fig. 1 Selected quality factors with their percentage

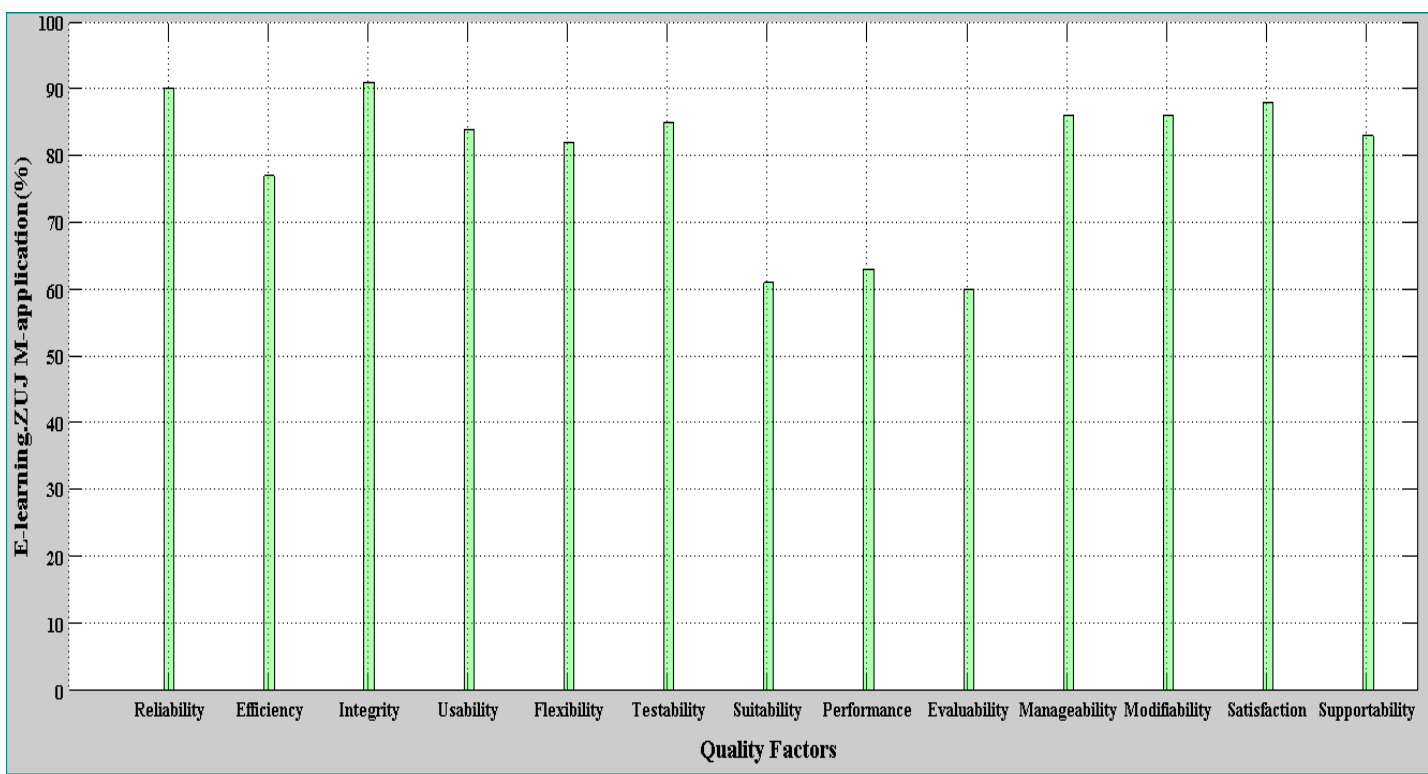

Fig. 2 Quality factor availability (\%) in the Elearning.ZUJ mobile application 
Fig. 2 shows that the quality factors most available in the Elearning.ZUJ mobile application from the point of view of the students and instructors were reliability, integrity, manageability, modifiability and satisfaction. All of which earned a rating of greater than $85 \%$. Thus, these aspects should be ignored in the future; instead, we must try to improve and focus on them to progress. From another perspective, the percentage of respondents who were satisfied with suitability, performance and evaluability factors was low. We attribute this to the reasoning we discussed in the preceding paragraph of this section.

In this pilot experiment, the quality model from students and instructors' perspectives that can be proposed will include and focus on the following quality factors: reliability, integrity, usability and satisfaction. These findings were given to the decision-makers of the Al-Zaytoonah University of Jordan, and they have enhanced the Elearning.ZUJ mobile application with more work to be done in the future. However, this quality model can be changed if the COVID-19 pandemic is over and the teaching and learning in the university is in face-to-face again.

\section{Conclusions and Future Work}

This study aims to look into the quality factors that influence students and instructors' use of the Elearning.ZUJ mobile application at the Al-Zaytoonah University of Jordan. Moreover, the study aims to determine how well the quality factors matched the aspirations of students and instructors who used the application throughout the academic year 2020-2021. In predicting actual usage of the Elearning.ZUJ mobile application for educational activities, the outcomes of this study were compatible with the essential quality factors. The findings revealed the following: (1) a significant positive relationship exists between the perceived reliability and demand for using E-learning applications and the following perceived quality factors: reliability, efficiency, integrity, usability, satisfaction, and supportability; (2) a significant positive relationship exists between the perceived benefit and behavioral intention to use E-learning mobile applications; and (3) significant positive relationships exist between reported ease-of-use and reported usefulness and attitudes about using the Elearning.ZUJ mobile application according to the beneficiaries' responses. This study shows that, in light of the technological revolution, the quality elements offered by apps used for E-learning purposes, such as Elearning.ZUJ, have a fundamental effect on the demand for such applications presently and in the future. This finding means that those concerned about quality should anticipate the factors that influence students' desire to employ technology in their academic pursuits and activities.

This study produced valuable data that explain the elements that influence students' actual use of technology in higher education institutions. However, the study has a shortcoming that future research can address. 


\section{References}

[1] Warschauer, M. (2007). A teacher's place in the digital divide. Yearbook of the National Society for the Study of Education, 106(2), 147-166.

[2] Warschauer, M., Zheng, B., Niiya, M., Cotten, S., \& Farkas, G. (2014). Balancing the one-to-one equation: Equity and access in three laptop programs. Equity \& Excellence in Education, 47(1), 46-62.

[3] Davis, F. (1989). Perceived usefulness, perceived ease of use, and user acceptance of information technology. MIS Quarterly, 13(3), 319-340.

[4] Davis, F., Bagozzi, R., \& Warshaw, P. (1989). User acceptance of computer technology: a comparison of two theoretical models. Management Science, 35(8), 982-1003.

[5] Bahaj, S., Aljaaidi, K., \& Ahmed, T. (2019). Using TAM model to empirically examine students' attitudes toward e-services in college of business administration. Management Science Letters, 9(5), 651-660.

[6] Nedeva, V., \& Zlatev, Z. (2013). Quality of The Services Provided by A University Web Portal. Applied Researches in Technics, Technologies and Education, 1(3), 173-180.

[7] Khwaldeh, S. M., Al-Hadid, I., \& Masadeh, R. E. (2017). The association between e-services web portals information quality and ICT competence in the Jordanian universities. Asian Social Science, 13(3), 156.

[8] Kim-Soon, N., Rahman, A., \& Ahmed, M. (2014). E-service quality in higher education and frequency of use of the service. International Education Studies, 7(3). DOI:10.5539/ies.v7n3p1

[9] Hamilton, E. (2019). Why mobile apps are important for your business?

Retrieved July 13, 2020 from:

https://www.techtimes.com/brandspin/242588/20190504/why-mobile-apps-

are-important- for-your-business.htm

[10] Bobby, R. (2018). Importance of mobile apps in todays' world. Retrieved July 13, 2020 from: https://yourstory.com/mystory/importance-of-mobile-apps-intodays-world-08ou $5 \mathrm{wgu} 7 \mathrm{~g}$

[11] Roy, S. (2017). 5 benefits of using mobile apps in education. Retrieved July 13, 2020 from: https://E-learningindustry.com/ mobile-apps-in-education-5benefits

[12] Lee, J. W., Becker, K., \& Potluri, R. M. (2016). Antecedents of Corporate Adoption of Social Media and the Role of the Technology Acceptance Model in the Path. Journal of Asian Finance, Economics and Business, 3(2), 67-76. https://doi. org/10.13106/jafeb.2016.vol3.no2.67. 
[13] Oza, H. (2017). The importance of mobile applications in everyday life. Retrieved July 13, 2020 from: https://www. hyperlinkinfosystem.com/blog/theimportance-of-mobile-applications-in-everyday-life\#

[14] Hwang, G. J., \& Tsai, C. C. (2011). Research trends in mobile and ubiquitous learning: A review of publications in selected journals from 2001 to 2010. British Journal of Educational Technology, 42(4), E65-E70.

[15] Frohberg, D., Göth, C., \& Schwabe, G. (2009). Mobile learning projects-a critical analysis of the state of the art. Journal of computer assisted learning, 25(4), 307-331.

[16] Looi, C. K., Zhang, B., Chen, W., Seow, P., Chia, G., Norris, C., \& Soloway, E. (2011). 1: 1 mobile inquiry learning experience for primary science students: A study of learning effectiveness. Journal of Computer Assisted Learning, 27(3), 269-287.

[17] Wong, L. H., \& Looi, C. K. (2011). What seams do we remove in mobileassisted seamless learning? A critical review of the literature. Computers \& Education, 57(4), 2364-2381.

[18] Fishbein, M., \& Ajzen, I. (1975). Belief, attitude, intention and behaviour: An introduction to theory and research. Reading, MA: Addison-Wesley.

[19] Ajzen I., \& Fishbein, M. (1980). Understanding Attitudes and Predicting Social Behavior. Englewood Cliffs, NJ: Prentice Hall.

[20] Mallya, J., \& Lakshminarayanan, S. (2017). Factors Influencing Usage of Internet for Academic Purposes Using Technology Acceptance Model. Journal of Library \& Information Technology, 37(2).

[21] Ratna, P. A., \& Mehra, S. (2015). Exploring the acceptance for e- learning using technology acceptance model among university students in India. International Journal of Process Management and Benchmarking, 5(2), 194210.

[22] Farahat, T. (2012). Applying the technology acceptance model to online learning in the Egyptian universities. Procedia-Social and Behavioral Sciences, 64, 95-104.

[23] Dhume, S. M., Pattanshetti, M. Y., Kamble, S. S., \& Prasad, T. (2012). Adoption of social media by business education students: Application of Technology Acceptance Model (TAM). In: 2012 IEEE International Conference on Technology Enhanced Education (ICTEE) (pp. 1-10). IEEE.

[24] M. Abdul Jawad, A. Ahmad, K. Jaber, A. Thunibat, E. Abu Maria, A. Khasawneh, et al., "Evaluating and Adopting E-learning Systems in AlZaytoonah University of Jordan," International Journal of Advances in Soft Computing and its Applications, vol. 12, 11/08 2020. 
[25] Abdallah, M., Jaber, K. M., Salah, M., Jawad, M. A., AlQbailat, N., \& Abdalla, A. (2021, July). An E-learning Portal Quality Model: from Al-Zaytoonah University Students' Perspective. In 2021 International Conference on Information Technology (ICIT) (pp. 553-557). IEEE.

\section{Notes on contributors}

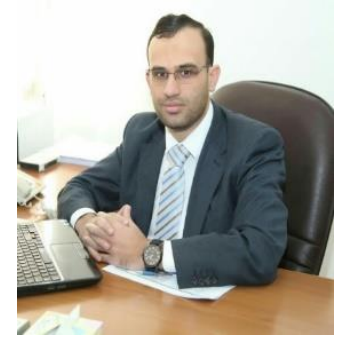

Khalid Mohammad Jaber is an Associate Professor of Computer Science at the Faculty of Science and Information Technology at the Al-Zaytoonah University of Jordan, director of the E-learning and Open Educational Resource Center, and IEEE Senior member. He has published more than 20 papers in journals and conference proceedings. Moreover, Dr Jaber has led four research grants, supervised Master students, and received a fellowship award.

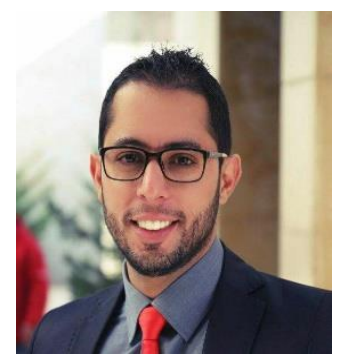

Mohammad Abduljawad had finished his Bachelor and master Degree from Al-Zaytoonah University of Jordan (ZUJ). Majoring in Computer Science Since 2017, he has been a teacher and Researcher at ZUJ and Published more than 4 Papers internationally. His research interests, mainly in artificial intelligence and Elearning, have successfully granted some research grants from the ZUJ.

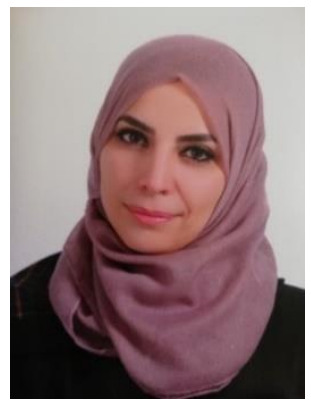

Amal Qassed Ahmad is an instructor at the Department of Electrical Engineering, Al-Zaytoonah University of Jordan, Amman, Jordan. Her main research interests include data security, network performance analysis, network security, wireless networks and ad hoc networks, digital image processing and computer architecture. She published several research articles in international journals

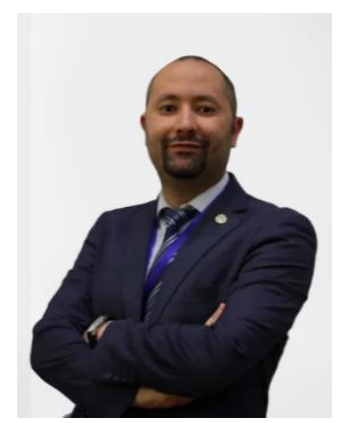

Mohammad Abdallah Received the Ph.D. degree in Software Engineering from Durham University, UK in 2012. The M.Sc. degree in Software Engineering from Bradford University, UK in 2008. BSc in Computer Science from Al-Zaytoonah University of Jordan in 2007. Currently, he is the Director of Technology Transfer Office and an Assistant Professor of Software Engineering Department in Al-Zaytoonah University. His research interests in Software Engineering field, such as, Big Data and Quality Engineering. 
Mohammad is an ACM Professional member-SIGCHI and SIGSOFT Member, Board Member in Jordan Computer Society (JCS).

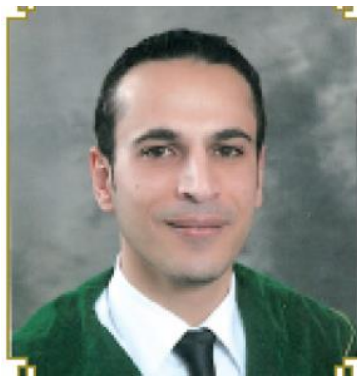

Mousa Salah had finished his master degree from AlThe Arab Academy for Banking and Financial Sciences. Majoring in computer information systems Since 2006, he has been a teacher and Researcher at ZUJ. His research interests, mainly in 3D professional, he have successfully granted some research grants from the ZUJ.

Nouh Alhindawi is an Associate Professor in the Field

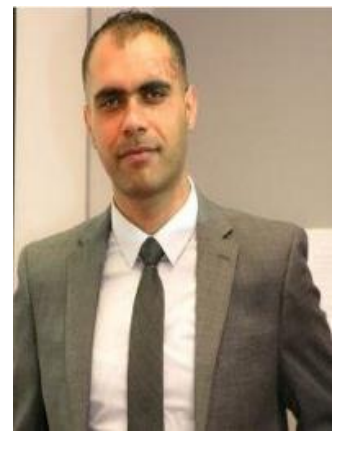
of Software Engineering and Computer Science. Now, acting as the Director of Information Technology and Electronic Transformation Directorate, Ministry of Higher Education and Scientific Research (MoHESR) since 2018. A key aspect of his role is leading the National Open Education Resource Center in Jordan which established recently to act as an umbrella for education resources in Jordan. He is a member of a number of national committees specialized in ELearning development in Jordan. Worked previously as Director for Computer Center, Jadara University -2015 - 2018, faculty member, and as University Advisor for Jadara University to Digital Transformation Policies. He obtained his PhD in Computer Science / Software Engineering from Kent State University, USA, in 2013. He obtained his Master Degree from Al-Balqa Applied University, Jordan, in 2006 and the BS degree from Yarmouk University, Jordan, in 2004. His research interests are in Software Engineering, Information Retrieval, Online Education Development and Enhancement. 